\title{
Carbonation Depth Model and Prediction of Hybrid Fiber Fly Ash Concrete
}

\author{
Jing-shuang Zhang $\mathbb{D}^{1,2}$ Meng Cheng, ${ }^{1,2}$ and Jian-hua Zhu ${ }^{1,2}$ \\ ${ }^{1}$ Engineering Research Center of Underground Mine Construction, Ministry of Education, \\ Anhui University of Science and Technology, Huainan 232001, Anhui, China \\ ${ }^{2}$ School of Civil Engineering and Architecture, Anhui University of Science and Technology, Huainan 232001, Anhui, China
}

Correspondence should be addressed to Jing-shuang Zhang; hnaust@163.com

Received 6 January 2020; Revised 29 April 2020; Accepted 27 May 2020; Published 18 June 2020

Academic Editor: Marco Corradi

Copyright (C) 2020 Jing-shuang Zhang et al. This is an open access article distributed under the Creative Commons Attribution License, which permits unrestricted use, distribution, and reproduction in any medium, provided the original work is properly cited.

\begin{abstract}
The concrete is weakly alkaline, the alkalinity of the concrete will be reduced after being carbonized, and the protective effect of the concrete on the steel bar will be weakened, even leading to corrosion of the steel bar. In this paper, fly ash is used to replace cement in the same amount, and basalt fiber and polypropylene fiber are added in a certain amount to make hybrid fiber fly ash concrete. Through rapid carbonation test, the influence of carbonation time and fly ash content on carbonation performance of hybrid fiber fly ash concrete is studied. The curve is fitted according to a single factor carbonation model with fly ash content as the main parameter, and the fitting curve and prediction formula are obtained. The results show that, in the same carbonization time, compared with the concrete without fly ash, the concrete with fly ash content of 5\%,10\%,20\%, and 30\% has average carbonization depth promotion rates of $6.4 \%, 14.9 \%, 59.8 \%$, and $73.5 \%$. When the fly ash content varies in the range of $10 \% \sim 20 \%$, the carbonation resistance of hybrid fiber concrete changes most sensitively. At the same fly ash content, with the increase of carbonization time, the carbonization depth of concrete increases by $41.7 \% \sim 62.3 \%$; Through the verification of the fitting curve and fitting formula obtained after fitting, it is concluded that the error of the prediction formula of carbonation depth of hybrid fiber fly ash concrete is within $9.1 \%$, and the error of carbonation depth of $14 \mathrm{~d}$ and $28 \mathrm{~d}$ is within $4.3 \%$. Replacing cement with fly ash has certain engineering significance and can achieve the purpose of recycling waste materials.
\end{abstract}

\section{Introduction}

With the development of industry, fly ash has become one of the industrial wastes with large displacement in China. Fly ash is a by-product of combustion, accounting for about 60-88 of the total combustion residue of coal-fired power plants. Worldwide, annual production is estimated at 750 million to 100 million tons $[1,2]$. If left untreated, it will not only occupy land resources but also cause harm to living creatures and the environment $[3,4]$. However, fly ash can be recycled. At present, it has been applied in building materials [5-12], agriculture [13-16], atmospheric control [17-20], and wastewater treatment [21-25], etc., so there is a large space for its utilization. At the same time, the cement production process will emit a large amount of $\mathrm{CO}_{2}$ into the atmosphere, and the increase of $\mathrm{CO}_{2}$ concentration in the air will intensify the carbonation reaction of concrete to a certain extent, bringing certain losses to the economy. The carbonization process of concrete is essentially a process in which $\mathrm{CO}_{2}$ in the air invasions into concrete and causes a series of chemical reactions of alkaline substances inside concrete to form carbonate and water, reducing the alkalinity of concrete $[26,27]$. With the increasingly serious carbonization phenomenon, the durability problem of concrete caused by this gradually deepens and may even lead to the destruction of concrete structure.

At present, scholars have carried out a lot of research studies on the carbonization properties of hybrid fiber fly ash concrete. More and more scholars have improved the carbonation resistance of concrete by adding fibers to the 
concrete. This is because after the fibers are added into the concrete, due to the connection effect between the fibers, the fibers are connected with each other to form a network, thereby reducing aggregate subsidence in the concrete, hindering segregation of concrete mixture, and reducing bleeding of the concrete, thus reducing pore channels in the concrete. At the same time, a large amount of fibers can block capillaries in mortar, reduce or prevent formation, growth, and expansion of cracks in the concrete, and block the connection of cracks, thereby weakening the diffusion path of $\mathrm{CO}_{2}$, inhibiting diffusion of $\mathrm{CO}_{2}$, and improving the carbonation resistance of the concrete [28]. Cheng [29] studied that steel fiber, polypropylene fiber, and hybrid fiber have different degrees of improvement in carbonization resistance when the volume mixing rate is $1 \% \sim 3 \%$. The order of improvement is hybrid fiber series, polypropylene fiber series, and steel fiber series. According to Zhang et al. [30], carbonation resistance of concrete increases with the increase of the steel fiber content. Under the condition that the volume content of steel fiber remains unchanged, when the volume content of polypropylene fiber is $0.06 \%$, the improvement effect on the carbonization resistance of concrete is the most obvious. With the increase of the volume content of polypropylene fiber, the improvement effect gradually weakens. Kim et al. [31] found that, in the high-strength mixture, the carbonization rate of polypropylene fiber was faster, while that of steel fiber was slower. Zhang et al. [32] found that the fiber content increased from $0 \%$ to $2 \%$, and the compressive strength of polypropylene fiber and HPVA fiber reinforced carbon fiber reinforced composite first increased and then decreased, reaching the maximum value when the fiber content was $1 \%$. With the increase of fiber content, flexural strength and impact resistance were significantly improved. ECC materials reinforced with $2 \%$ polypropylene fibers show excellent carbonization durability with a maximum carbonization depth of only $0.8 \mathrm{~mm}$. Yuan et al. [33] obtained from carbonization test of polypropylene fiber concrete after high temperature that polypropylene fiber can effectively improve the carbonation resistance of concrete when the dosage is moderate. Bi and Zhao [34] studied the influence of hybrid fiber on the carbonation resistance of lightweight aggregate concrete by mixing two fibers in lightweight aggregate concrete. The results show that hybrid fiber can greatly improve the carbonation resistance of concrete under the condition of appropriate dosage. Zhu and Wang [35] concluded through carbonization test study on fly ash concrete with the content of $0 \sim 60 \%$ that the carbonization resistance of concrete would decline with the increase of fly ash content. Qiu and Ye [36] concluded through early curing time for ordinary concrete carbonation resistance experiments that concrete carbonization is strongly influenced by early standard curing time; the shorter the time, the greater the carbonation depth of concrete, especially when the early age of standard curing time is less than $3 \mathrm{~d}$ concrete carbonation depth of soil compared with the standard have $28 \mathrm{~d}$ increased by $50 \%$ $100 \%$. Jeon et al. [37] have concluded that the higher the replacement rate of BFS and fly ash is, the more obvious the carbonization acceleration of ternary mixed concrete is. This trend is due to the fact that, with the consumption of $\mathrm{Ca}(\mathrm{OH})_{2}$, its ability to maintain $\mathrm{pH}$ decreases, the amount of calcium decreases, and the replacement rate of BFS and fly ash increases. Kurda et al. [38] found that, with the increase of fly ash content, the carbonization of concrete increased significantly. After adding 30\% and 60\% fly ash, the carbonization rate was increased by 3 times and 6 times, respectively. At the same time, scholars have also carried out a lot of research studies on the concrete carbonization model [39-42].

In this paper, fly ash is used to replace cement equally; basalt fiber with volume ratio of $0.1 \%$ and polypropylene fiber with volume ratio of $0.2 \%$ are added. Through rapid carbonization test, the relationship between curing time, fly ash content, and carbonation performance of hybrid fiber fly ash concrete is obtained. Through curve fitting of the relationship between carbonation depth and time of hybrid fiber fly ash concrete, the fitting curve of fly ash adjustment coefficient and carbonation depth calculation formula are obtained. Through verification of carbonation depth calculation formula, it is proved that carbonation depth calculation formula has certain accuracy and provides certain theoretical data for practical application of engineering.

\section{Experimental Section}

2.1. Materials and Mix Proportion. The cement is P.O 42.5 ordinary Portland cement produced by Bagongshan cement factory in Huainan city, Anhui province. Fly ash is the second-grade fly ash from Pingwei power plant in Huainan city, Anhui province, composed of $\mathrm{SiO}_{2} 45.40 \%, \mathrm{Al}_{2} \mathrm{O}_{3}$ $33.51 \%, \mathrm{Fe}_{2} \mathrm{O}_{3}$ 5.28\%, $\mathrm{TiO} 4.72 \%, \mathrm{CaO} 3.15 \%, \mathrm{MgO} 2.82 \%$, and others $5.12 \%$. The length of basalt fiber is $6 \mathrm{~mm}$, the physical and mechanical properties are shown in Table 1, and the appearance characteristics are shown in Figure 1. The length of polypropylene fiber is $12 \mathrm{~mm}$, the physical and mechanical properties are shown in Table 1 , and the appearance characteristics are shown in Figure 1. Coarse aggregate is $5 \sim 20 \mathrm{~mm}$ gradation gravel, fine aggregate is medium sand from Huaihe River, and water is laboratory tap water. After considering such factors as strength and workability, the final mixing ratio of cement-sand-gravelwater is $446: 613: 1091: 250$.

2.2. Test Methods. Firstly, the sundries and uncleaned waste materials inside the concrete mold are cleaned; secondly, engine oil is brushed on the inner wall of the mold for demoulding; and finally, small holes at the bottom of the plastic mold are plugged with small pieces of paper to prevent slurry leakage.

Using a forced mixer for mixing to ensure uniformity, after weighing the hybrid fiber, it should be spread evenly by hand so that the fiber can be more evenly distributed in the concrete. The specific stirring method is shown in Figure 2.

After the mixing is completed, pour the concrete out of the mixing pot for molding, put it on the vibrating table for vibrating after the molding is completed, wipe off bubbles on 
Table 1: Physical and mechanical properties.

\begin{tabular}{lcccc}
\hline Fiber species & Density $\left(\mathrm{g} \cdot \mathrm{cm}^{-3}\right)$ & Elongation to fracture (\%) & Tensile strength (MPa) & Elastic modulus (GPa) \\
\hline Basalt fiber & 2.65 & 3.2 & $3000 \sim 3300$ & $90 \sim 110$ \\
Polypropylene fiber & 0.91 & $30 \sim 50$ & $365 \sim 600$ & $2.4 \sim 3.2$ \\
\hline
\end{tabular}

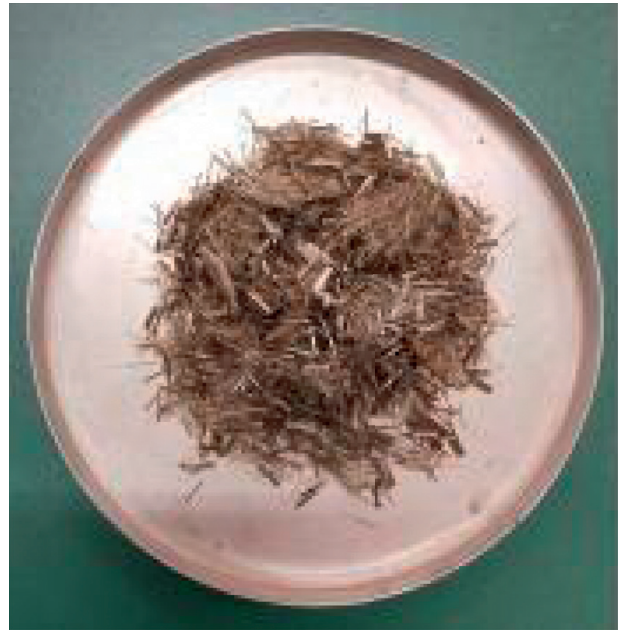

(a)

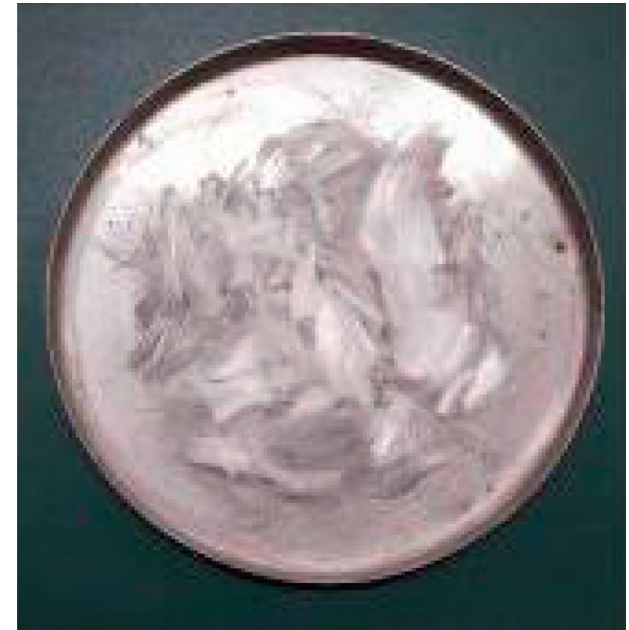

(b)

Figure 1: Fiber types: (a) basalt fiber; (b) polypropylene fiber.

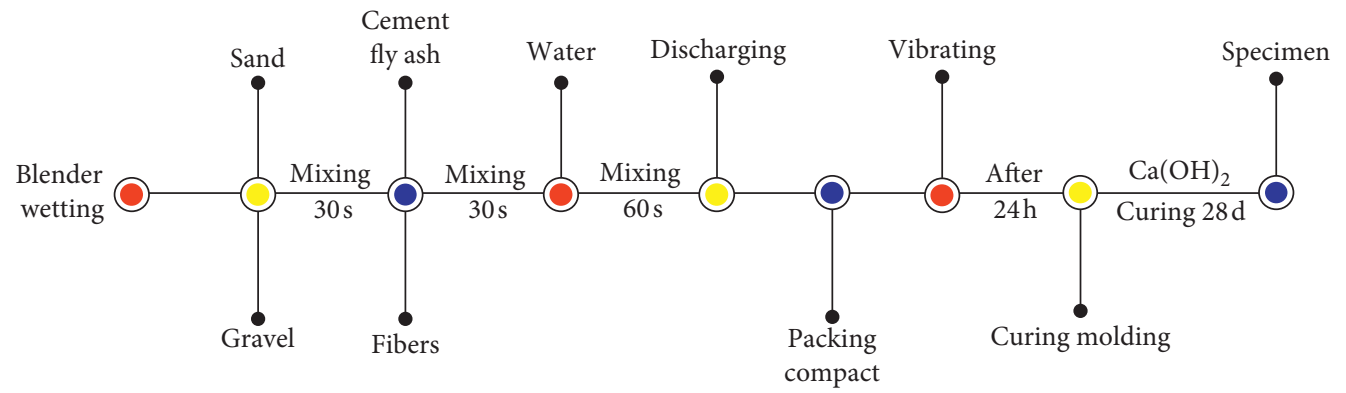

Figure 2: Concrete mixing method.

the concrete surface with a spatula, and stop vibrating when there are no more bubbles on the surface.

Standard curing for 24 hours shall be carried out on the vibrated specimen, and the specimen shall be put into saturated $\mathrm{Ca}(\mathrm{OH})_{2}$ solution with a temperature of $(20 \pm 2)^{\circ} \mathrm{C}$ for curing after the specimen number is completed.

2.3. Carbonization Test and Data Processing. Carbonization test was carried out in accordance with the relevant provisions of "standard test method for long-term performance and durability of ordinary concrete (GB/T 50082-2009)" [43]. The size of the test specimen is $100 \mathrm{~mm} \times 100 \mathrm{~mm} \times$ $400 \mathrm{~mm}$ prism test block. The test blocks were divided into five groups, three test blocks for each group. After standard curing for $28 \mathrm{~d}$, they were put into the oven with the temperature set at $60^{\circ} \mathrm{C}$ for $48 \mathrm{~h}$, and the oven was equipped with 101-3A constant temperature drying oven. After drying, paraffin was used to seal the remaining 5 surfaces except the upper surface with paraffin. As the upper surface of the carbonization surface, a parallel line was drawn every $10 \mathrm{~mm}$ along the length direction as the measuring point after the failure, and a vertical line was made every $80 \mathrm{~mm}$ as the cutting line. Put the lined test blocks into a carbonized box and keep the distance between test blocks above $50 \mathrm{~mm}$, as shown in Figure 3. After putting the test block into the carbonization box, seal the carbonization box and open the adjustment control panel of the carbonization box to keep the $\mathrm{CO}_{2}$ concentration at $(70 \pm 5) \%$ and the relative humidity at $(20 \pm 2)^{\circ} \mathrm{C}$. The test block was taken out in $3 \mathrm{~d}, 7 \mathrm{~d}$, $14 \mathrm{~d}$, and $28 \mathrm{~d}$, and the cutting line was cut according to the vertical line with an interval of $80 \mathrm{~mm}$ drawn previously. After each cutting, the cutting surface of the remaining part was sealed with paraffin and carbonized until 28 days, and the final breaking pattern was completed. The cut part was cleaned on the surface, and then $1 \%$ phenolphthalein alcohol 


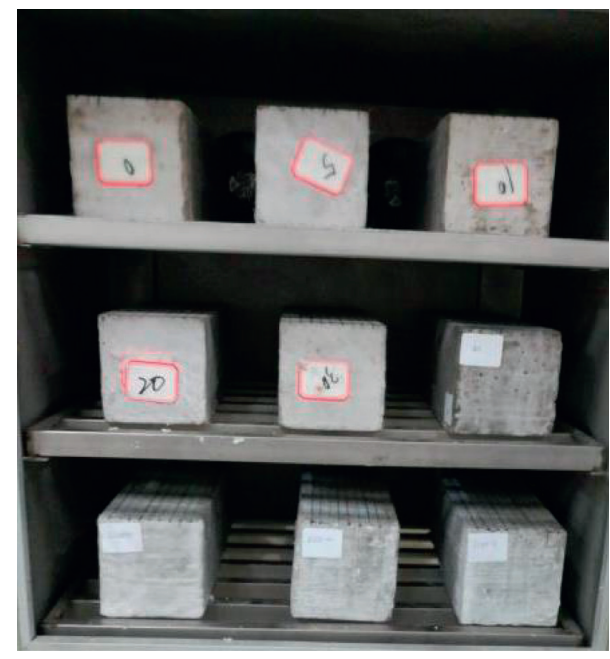

FIgURE 3: Specimen placement picture.

treatment was applied to the surface. After 30 seconds, the carbonization depth of the measuring point was measured with vernier caliper, accurate to $0.1 \mathrm{~mm}$. If there are gravel particles at the measuring point, the carbonization depth is taken as the average value of adjacent measuring points. After all data measurements are completed, the carbonization depth is calculated according to .

$$
\overline{d_{t}}=\frac{1}{n} \sum_{1}^{n} d_{i},
$$

where $\overline{d_{t}}$ is average carbonization depth, $\mathrm{mm} ; d_{i}$ is carbonization depth of measuring point, $\mathrm{mm}$; and $n$ is number of measuring points.

\section{Test Results}

3.1. Carbonation Depth. The carbonization depth of each specimen was calculated and recorded in Table 2 according to "Standard test method for long-term performance and durability of ordinary concrete (GB/T 50082-2009)."

3.2. Carbonization Pictures. The carbonation pictures of concrete without fly ash and concrete with $30 \%$ replacement rate of fly ash with carbonation time of 3 days, 7 days, 14 days, and 28 days are, respectively, selected for comparative analysis, as shown in Figures 4 and 5.

\section{Results Discussions}

\subsection{Effect of Fly Ash Content on Carbonation Depth of} Concrete. In order to analyze the influence of fly ash content on the carbonation depth of concrete, the carbonation depth of hybrid fiber reinforced concrete (HFRC) with fly ash content of $0 \%, 5 \%, 10 \%, 20 \%$, and $30 \%$ varies with time, as shown in Figure 6.

Figure 6 is the carbonation depth values of concrete with different fly ash contents at different carbonation times. It can be seen from the figure that at the same carbonation time, with the increase of fly ash contents, the carbonation depth of concrete also increases, and the carbonation increase
TABLE 2: Average carbonization depth.

\begin{tabular}{lcccc}
\hline \multirow{2}{*}{ Numbering } & \multicolumn{4}{c}{ Carbonization depth $(\mathrm{mm})$} \\
& $3 \mathrm{~d}$ & $7 \mathrm{~d}$ & $14 \mathrm{~d}$ & $28 \mathrm{~d}$ \\
\hline PBC-FA0 & 4.8 & 6.8 & 10.1 & 15.2 \\
PBC-FA5 & 5.0 & 7.3 & 10.9 & 16.1 \\
PBC-FA10 & 5.3 & 7.9 & 11.7 & 17.8 \\
PBC-FA20 & 7.1 & 11.3 & 16.8 & 24.1 \\
PBC-FA30 & 7.7 & 12.5 & 17.9 & 26.2 \\
\hline
\end{tabular}

rate also increases gradually. The specific data are shown in Table 3. This is because fly ash has pozzolanic effect, and the increase of fly ash contents will consume the $\mathrm{Ca}(\mathrm{OH})_{2}$ content stored in concrete; thus, the carbonation resistance of concrete decreases and the carbonation depth increases.

The average increase rate of carbonation depth of concrete with various fly ash contents at $3 \mathrm{~d}, 7 \mathrm{~d}, 14 \mathrm{~d}$, and $28 \mathrm{~d}$ can be obtained; compared with concrete without fly ash, the average increase rate of carbonation depth of concrete with fly ash contents of $5 \%, 10 \%, 20 \%$, and $30 \%$ is $6.4 \%, 14.9 \%, 59.8 \%$, and $73.5 \%$. When the content of fly ash is increased from $0 \sim 5 \%$ and the carbonation depth of concrete is increased by $6.4 \%$, the carbonation depth of concrete is increased by $1.3 \%$ when the content of fly ash is less than $5 \%$. When the fly ash content is increased from $5 \%$ to $10 \%$ and the carbonation depth is increased by $8.5 \%$, the carbonation depth of concrete is increased by $1.7 \%$ for every $1 \%$ fly ash added. Similarly, when the fly ash content is increased from $10 \%$ to $20 \%$ and from $20 \%$ to $30 \%$, the carbonation depth of concrete is increased by $4.49 \%$ and $1.37 \%$, respectively, for every $1 \%$ fly ash added. It can be seen that when the fly ash content ranges from $10 \%$ to $20 \%$, the carbonization depth improvement rate is the highest for each $1 \%$ fly ash content. With the increase of fly ash content, the carbonization depth improvement brought by each $1 \%$ fly ash content increases first and then decreases, which indicates that the fastest carbonization depth change is in the range of $10 \% \sim 20 \%$.

According to Figure 6, it can also be seen that the carbonation depth change rate is the largest when the fly ash content is $10 \% \sim 20 \%$, which means the carbonation resistance change of concrete is the most sensitive when the fly ash content is $10 \% \sim 20 \%$. This is because when the content of fly ash is low, the filling effect of CSH gel, the secondary hydration reaction product of fly ash, on capillary pores can improve the consumption of $\mathrm{Ca}(\mathrm{OH})_{2}$ in the process of fly ash hydration, and the carbonization depth slightly increases. When the content of fly ash is high, due to the obvious reduction of cement content, $\mathrm{Ca}(\mathrm{OH})_{2}$ generated by hydration is greatly reduced, further reducing the rate of pozzolanic reaction, the number of $\mathrm{CSH}$ gel bodies is reduced, and the effect of accelerating carbonization by the reduction of alkali content greatly exceeds the improvement effect of CSH gel bodies on pore structure, thus leading to a significant reduction in the carbonation resistance of concrete $[44,45]$. When the content of fly ash is less than $10 \%$, the carbonation resistance of hybrid fiber concrete can reach the carbonation resistance of reference concrete. When the content of fly ash is more than $20 \%$, the carbonation 


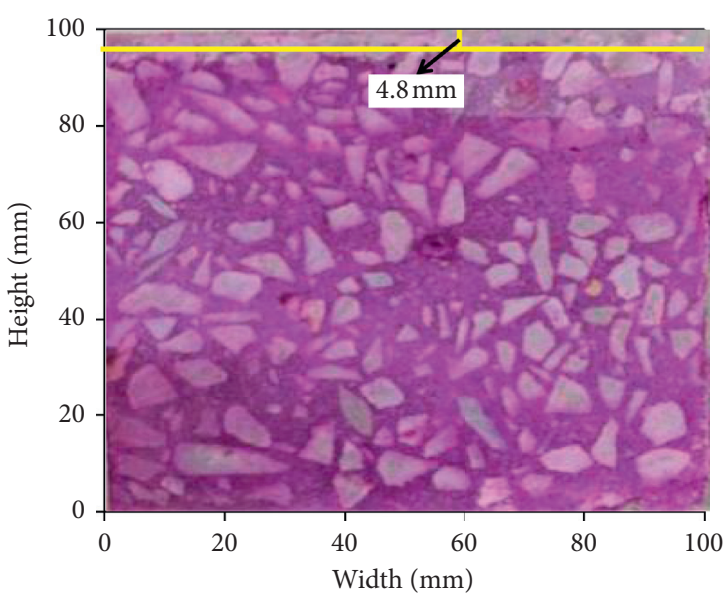

(a)

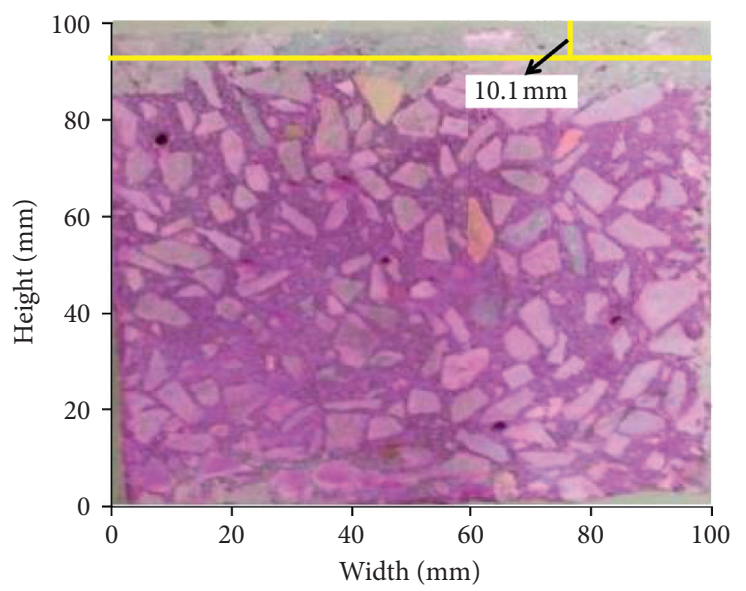

(c)

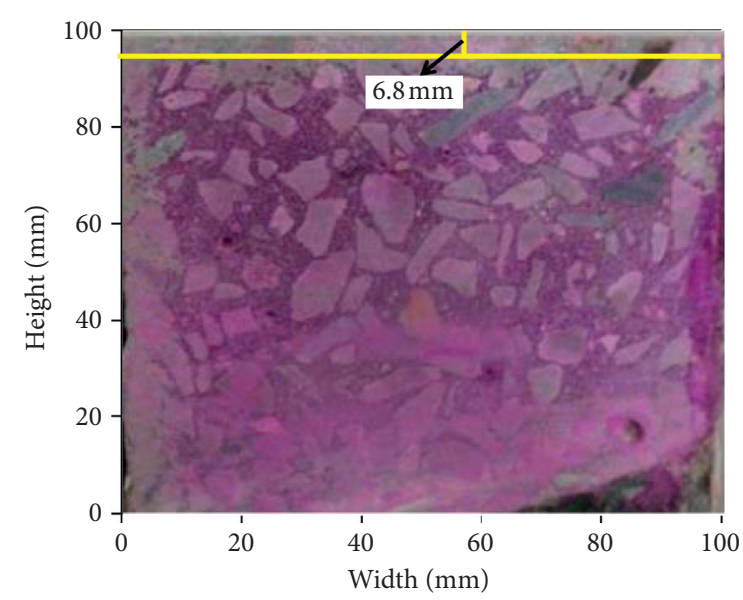

(b)

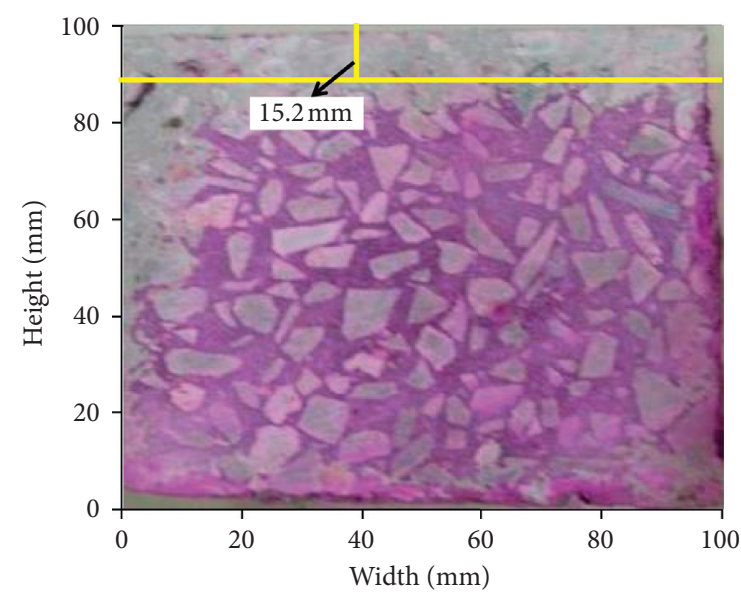

(d)

Figure 4: Carbonation depth of hybrid fiber concrete: (a) $3 \mathrm{~d}$ carbonization depth, (b) $7 \mathrm{~d}$ carbonization depth, (c) $14 \mathrm{~d}$ carbonization depth, and (d) $28 \mathrm{~d}$ carbonization depth.

resistance of hybrid fiber fly ash concrete is much lower than that of reference concrete. With the increase of fly ash content, the carbonation depth of concrete increases continuously, that is, the carbonation depth of concrete is positively correlated with the fly ash content. This shows that fly ash weakens the carbonation resistance of HFRC, and the greater the content, the more obvious the effect.

\subsection{Influence of Carbonization Time on Early Carbonization} Depth of Hybrid Fiber Concrete. There are many factors that affect the carbonization depth of hybrid fiber fly ash concrete, of which carbonization time is one of the important factors [46, 47]. According to the analysis in Table 2 and Figure 7, with the increase of carbonization time, the carbonization depth increases by $41.7 \%, 48.5 \%$, and $50.5 \%$, respectively, when the content of fly ash is $0 \%$. When the content of fly ash is $5 \%$, the carbonization depth increases by $46 \%, 49.3 \%$, and $47.7 \%$, respectively. When the content of fly ash is $10 \%$, the carbonization depth increases by $49.1 \%, 48.1 \%$, and $52.1 \%$, respectively. When the content of fly ash is $20 \%$, the carbonization depth increased by $59.2 \%$, $55 \%$, and $48.7 \%$, respectively. When the fly ash content was $30 \%$, the carbonization depth increased by $62.3 \%, 43.2 \%$, and $46.4 \%$, respectively. According to the analysis of the results, the carbonation depth of concrete increases by $41.7 \% \sim 62.3 \%$ with the increase of carbonation time under the same fly ash content. From this, we can draw a conclusion that, with the increase of carbonization time, the carbonation depth of each group of concrete is getting larger and larger. This is because the pozzolanic reaction of fly ash concrete will be accelerated and carried out more thoroughly with the extension of curing age, and the effects of pore refinement, filling of active substances, and improvement of transition zone structure will be more obvious, thus further improving the compactness of concrete. With the decrease of voids and the improvement of pore structure, the infiltration of $\mathrm{CO}_{2}$ gas becomes more difficult, thus improving the carbonation resistance of concrete. Therefore, with the extension of curing age, the carbonation resistance of concrete with large amount of fly ash is obviously improved $[48,49]$. 


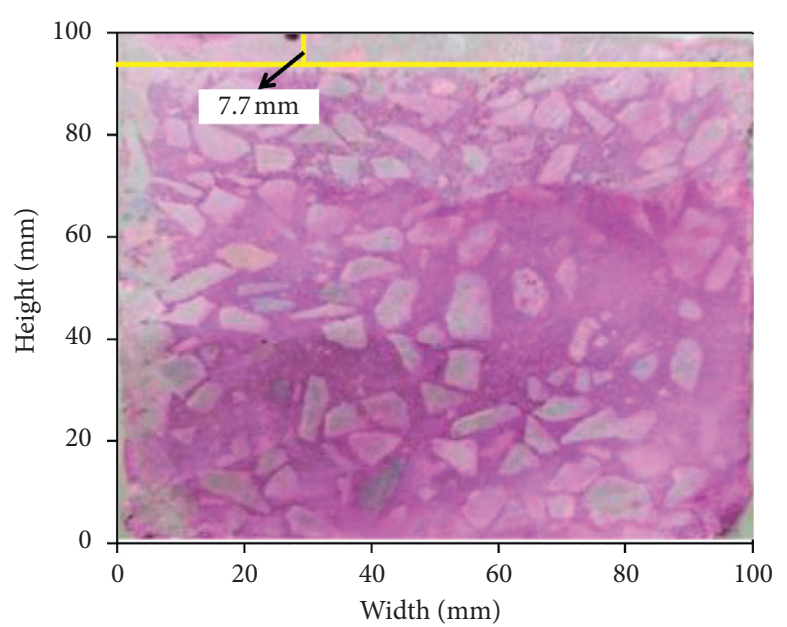

(a)

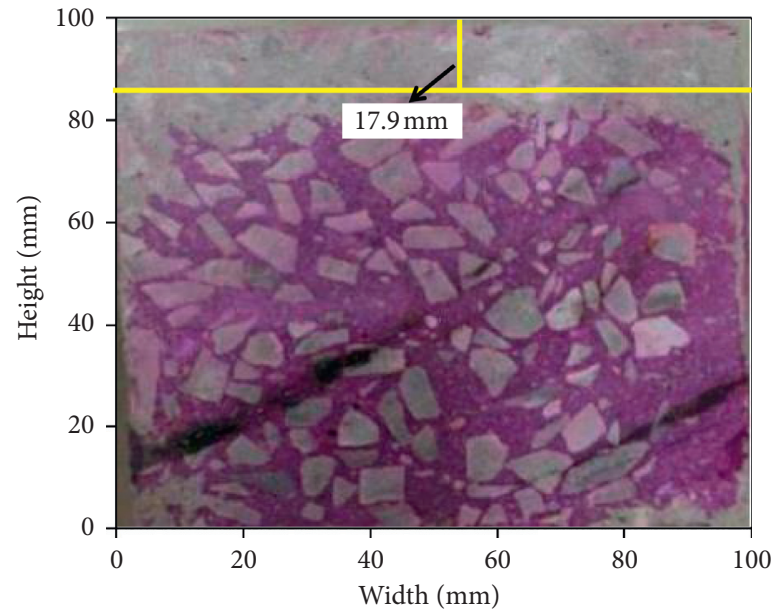

(c)

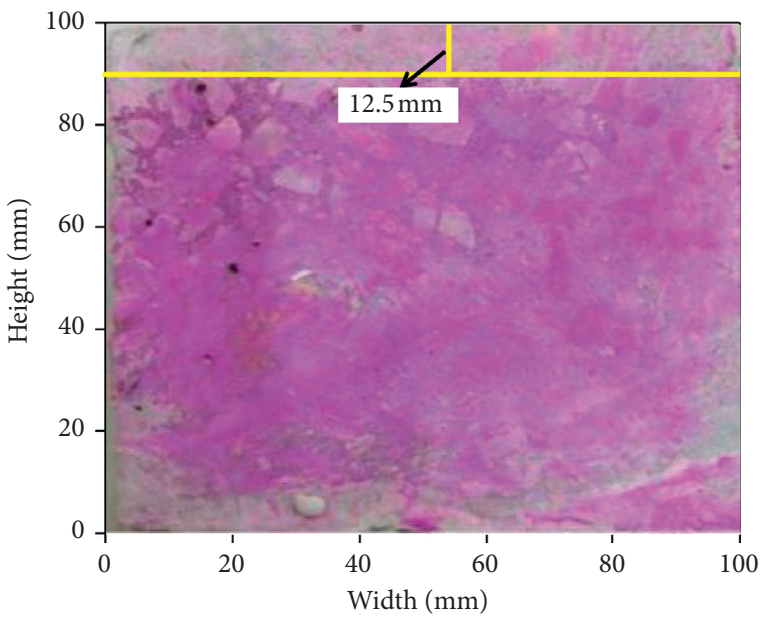

(b)

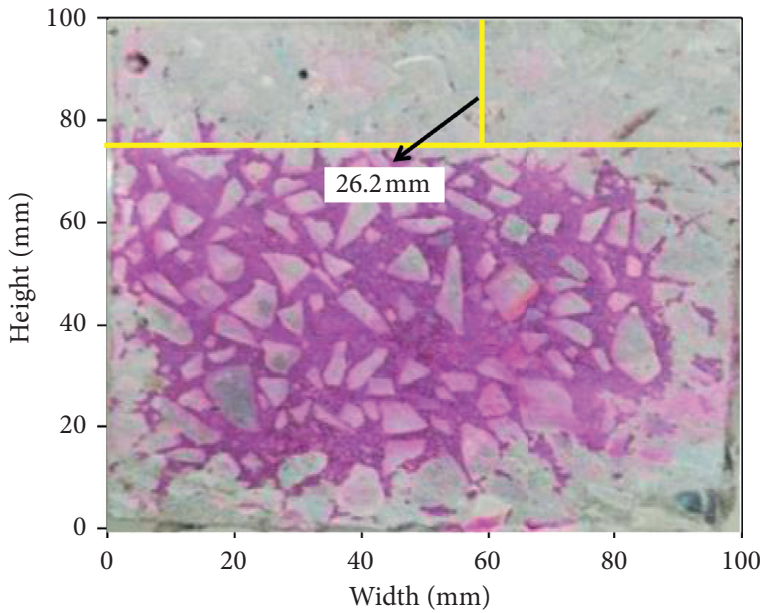

(d)

Figure 5: Carbonation depth of hybrid fiber concrete with 30\% fly ash substitution rate: (a) $3 \mathrm{~d}$ carbonization depth, (b) $7 \mathrm{~d}$ carbonization depth, (c) $14 \mathrm{~d}$ carbonization depth, and (d) $28 \mathrm{~d}$ carbonization depth.

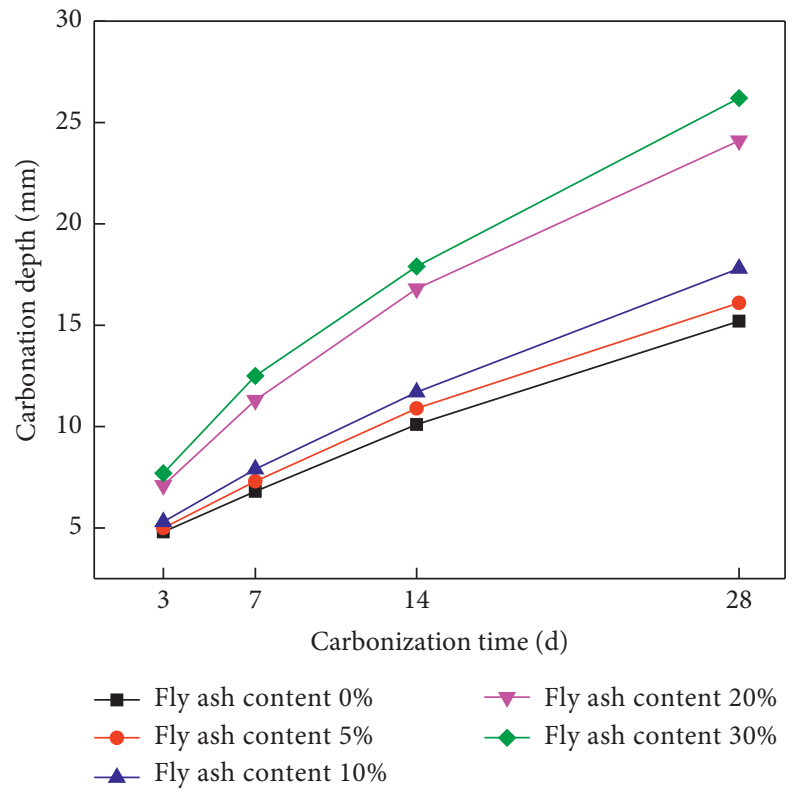

FIGURE 6: Relationship between carbonation depth and time of hybrid fiber fly ash concrete. 
TABLE 3: Influence of fly ash content on carbonization depth of hybrid fiber concrete.

\begin{tabular}{|c|c|c|c|c|}
\hline \multirow{2}{*}{ Fly ash content (\%) } & \multicolumn{4}{|c|}{ The increase rate of HFRC carbonization depth after adding fly ash (\%) } \\
\hline & $3 \mathrm{~d}$ & $7 \mathrm{~d}$ & $14 \mathrm{~d}$ & $28 \mathrm{~d}$ \\
\hline 0 & 0 & 0 & 0 & 0 \\
\hline 5 & 4.2 & 7.4 & 7.9 & 5.9 \\
\hline 10 & 10.4 & 16.2 & 15.8 & 17.1 \\
\hline 20 & 47.9 & 66.2 & 66.3 & 58.6 \\
\hline 30 & 60.4 & 83.8 & 77.2 & 72.4 \\
\hline
\end{tabular}

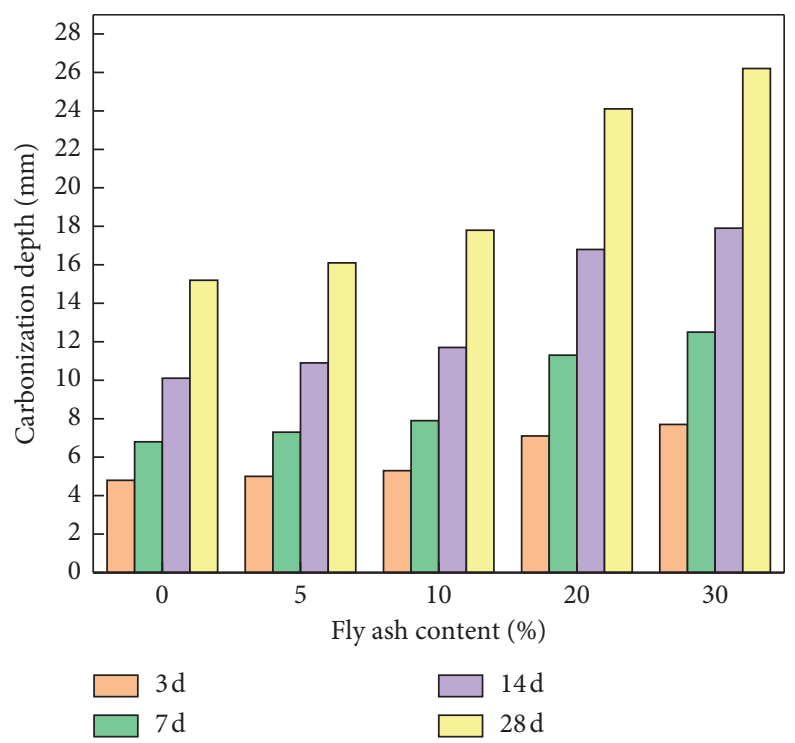

FIGURE 7: Effect of carbonizationg time on early carbonization depth.

\section{Carbonization Model and Prediction of Carbonization Depth}

A variety of experimental studies have been carried out on carbonization models at home and abroad, and many carbonization models have also been proposed. Among them, equation (2) is generally accepted:

$$
X_{\mathrm{C}}=a \sqrt{t},
$$

where $X_{\mathrm{C}}$ is carbonization depth ( $\left.\mathrm{mm}\right) ; a$ is carbonization coefficient; and $t$ is carbonization time (d).

The variable of this test is the fly ash content, so it is a single factor carbonization model with the fly ash content as the main parameter, and equation (3) is selected:

$$
X_{\mathrm{C}}=a b \sqrt{t} \text {, }
$$

where $X_{\mathrm{C}}$ is carbonization depth $(\mathrm{mm})$; $a$ is fly ash adjustment coefficient; $b$ is comprehensive adjustment coefficient of other factors; and $t$ is carbonization time (d).

Each curve in Figure 6 is fitted with $X_{\mathrm{C}}=c \sqrt{t}$ (where $c=a * b$ ), and the fitting curves and fitting results are shown in Figure 8 and Table 4, respectively.
When the content of fly ash is 0 , the factor of fly ash has no influence on the carbonization depth, so $a=1$, and the carbonization depth is $X_{\mathrm{C}}=a b \sqrt{t}=b \sqrt{t}$. From Table 4, it can be seen that the carbonization depth fitting function is $X_{\mathrm{C}}=2.78 \sqrt{t}$ when the content of fly ash is 0 , and $b=2.78$. Therefore, the calculation formula of carbonation depth can be expressed as $X_{\mathrm{C}}=2.78 a \sqrt{t}$. By comparing $X_{\mathrm{C}}$ $=2.78 a \sqrt{t}$ with the fitting function in Table 4 , the adjustment coefficient of each fly ash content can be obtained, as shown in Table 5.

Fit the adjustment coefficient of fly ash and the relationship between the amount of fly ash, and record the amount of fly ash as P. If the amount of fly ash is $30 \%$, then $P=30$, and obtain the functional relationship between the adjustment coefficient and the amount of fly ash, as shown in Figure 9.

It can be seen that the correlation coefficient $R^{2}=0.998$. According to the fitting function, the relationship between fly ash adjustment coefficient and fly ash content can be obtained as follows:

$$
a=1.753-\frac{0.76}{1+e^{(P-14.59) / 3.748}},
$$

where $a$ is fly ash adjustment coefficient and $P$ is fly ash content (\%) so that that calculation formula to calculate the carbonization depth can be obtained as follows: 


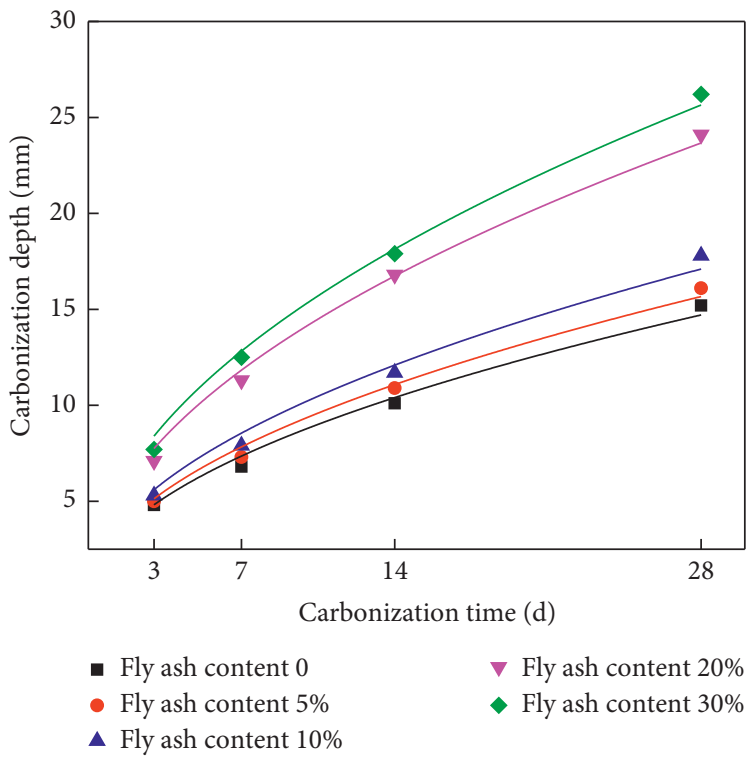

FIGURE 8: Carbonation depth fitting curve of hybrid fiber concrete with different powder and fly ash contents.

TABLE 4: Fitting function of carbonation depth and carbonation time of hybrid fiber concrete.

\begin{tabular}{lccc}
\hline Numbering & Fly ash content $(\%)$ & Fitting function & Correlation coefficient $\left(R^{2}\right)$ \\
\hline PBC-FA0 & 0 & $X_{\mathrm{C}}=2.78 \sqrt{t}$ & 0.990 \\
PBC-FA5 & 5 & $X_{\mathrm{C}}=2.96 \sqrt{t}$ & 0.993 \\
PBC-FA10 & 10 & $X_{\mathrm{C}}=3.23 \sqrt{t}$ & 0.987 \\
PBC-FA20 & 20 & $X_{\mathrm{C}}=4.74 \sqrt{t}$ & 0.994 \\
PBC-FA30 & 30 & $X_{\mathrm{C}}=4.85 \sqrt{t}$ & 0.995 \\
\hline
\end{tabular}

TABle 5: Adjustment coefficient of fly ash.

\begin{tabular}{lccc}
\hline Fly ash content (\%) & Fitting function & Calculation formula of carbonization depth & Fly ash adjustment coefficient $a$ \\
\hline 0 & $X_{\mathrm{C}}=2.78 \sqrt{t}$ & $X_{\mathrm{C}}=2.78 a \sqrt{t}$ & 1.00 \\
5 & $X_{\mathrm{C}}=2.96 \sqrt{t}$ & $X_{\mathrm{C}}=2.78 a \sqrt{t}$ & 1.06 \\
10 & $X_{\mathrm{C}}=3.23 \sqrt{t}$ & $X_{\mathrm{C}}=2.78 a \sqrt{t}$ & 1.16 \\
20 & $X_{\mathrm{C}}=4.74 \sqrt{t}$ & $X_{\mathrm{C}}=2.78 a \sqrt{t}$ & 1.61 \\
30 & $X_{\mathrm{C}}=4.85 \sqrt{t}$ & $X_{\mathrm{C}}=2.78 a \sqrt{t}$ & 1.74 \\
\hline
\end{tabular}

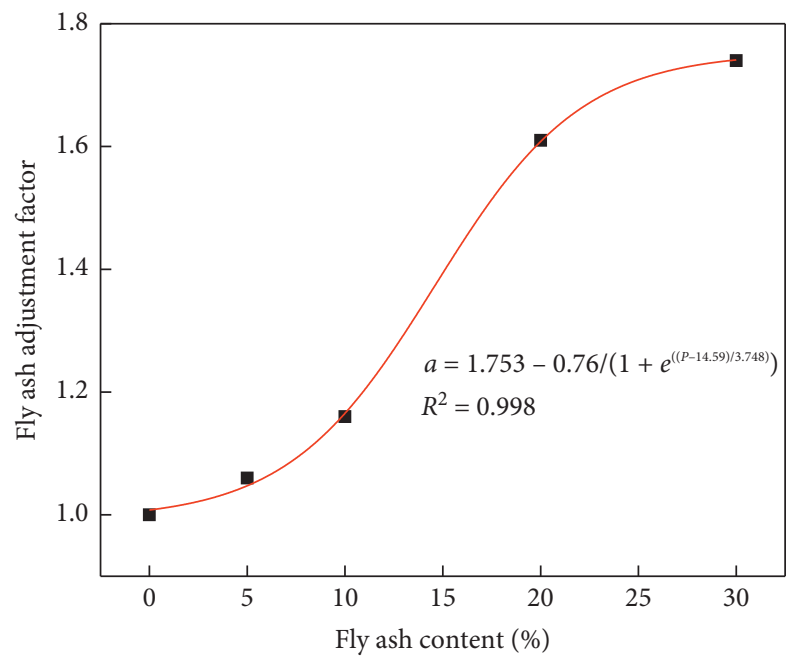

Figure 9: Fitting curve of the fly ash adjustment coefficient. 
TABLE 6: Comparison of predicted and measured carbonization depth.

\begin{tabular}{lcccc}
\hline Carbonization time $(\mathrm{d})$ & Fly ash content $(\%)$ & Test result $X_{\mathrm{C}}(\mathrm{mm})$ & Calculation result $X_{\mathrm{C}}^{\prime}(\mathrm{mm})$ & Error $\left(X_{\mathrm{C}}^{\prime}-X_{\mathrm{C}}\right) / X_{\mathrm{C}}(\%)$ \\
\hline 3 & 0 & 4.8 & 4.9 & 2.1 \\
3 & 5 & 5.0 & 5.6 & 0 \\
3 & 10 & 5.3 & 7.7 & 5.7 \\
3 & 20 & 7.1 & 8.4 & 8.5 \\
3 & 30 & 7.7 & 7.4 & 9.1 \\
7 & 0 & 6.8 & 7.7 & 8.8 \\
7 & 5 & 7.3 & 8.6 & 8.5 \\
7 & 10 & 7.9 & 11.8 & 4.4 \\
7 & 20 & 11.3 & 12.8 & 2.4 \\
7 & 30 & 12.5 & 10.5 & 4.0 \\
14 & 0 & 10.1 & 10.9 & 0 \\
14 & 5 & 10.9 & 12.1 & 3.4 \\
14 & 10 & 11.7 & 16.7 & -0.6 \\
14 & 20 & 16.8 & 18.1 & 1.1 \\
14 & 30 & 17.9 & 14.8 & -2.6 \\
28 & 0 & 15.2 & 15.4 & -4.3 \\
28 & 5 & 16.1 & 17.1 & -3.9 \\
28 & 10 & 17.8 & 23.7 & -1.7 \\
\hline
\end{tabular}

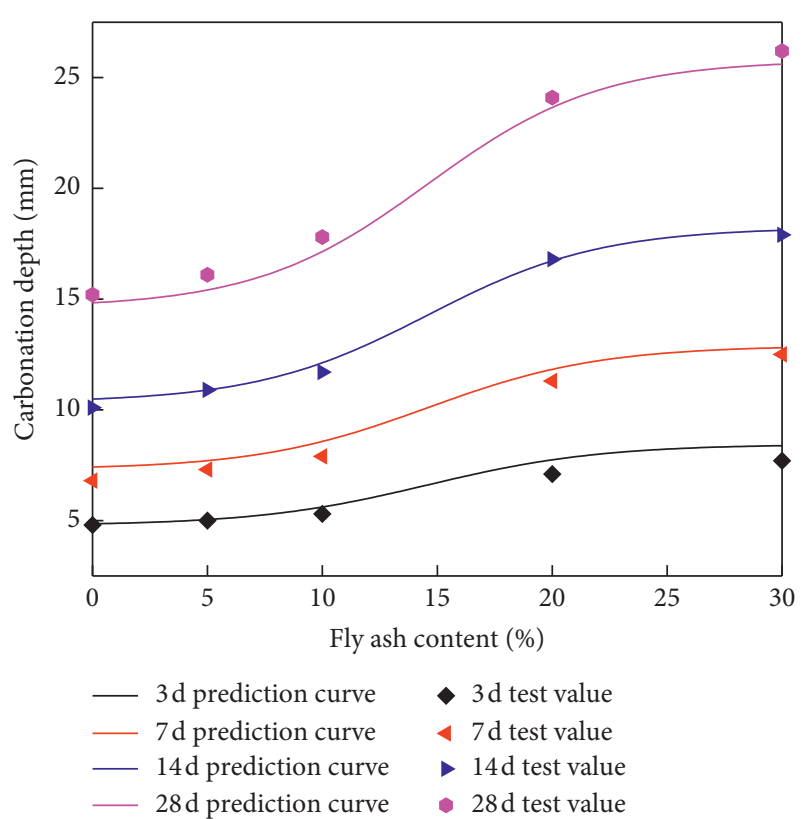

Figure 10: Predicted and experimental values of carbonation depth of hybrid fiber fly ash concrete.

$$
X_{\mathrm{C}}=a b \sqrt{t}=2.78 a \sqrt{t}=2.78 \times\left(1.753-\frac{0.76}{1+e^{(P-14.59) / 3.748}}\right) \sqrt{t} .
$$

Each parameter in the formula has the same meaning as above.

5.1. Verification of Carbonization Depth Calculation Formula. The accuracy of the carbonation depth calculation formula obtained by the above calculation still needs to be checked.
The carbonization time and fly ash content are brought into equation (5) to calculate the carbonization depth, and the carbonization test results and calculation results are subjected to error analysis. The obtained results are shown in Table 6 and Figure 10.

Negative error value indicates that the calculated value is smaller than the test result. As can be seen from Table 6, the maximum error is $9.1 \%$, the minimum error is 0 , the error is within $10 \%$, and the error of carbonation depth for $14 \mathrm{~d}$ and $28 \mathrm{~d}$ is within $5 \%$, so the accuracy of the carbonation depth calculation formula is relatively high.

\section{Conclusion}

(1) Fly ash reduces the carbonation resistance of hybrid fiber concrete, and the greater the content, the more obvious the effect.

(2) In the same carbonization time, compared with the concrete without fly ash, the concrete with fly ash content of $5 \%, 10 \%, 20 \%$, and $30 \%$ has average carbonization depth promotion rates of $6.4 \%, 14.9 \%$, $59.8 \%$, and $73.5 \%$. At the same fly ash content, with the increase of carbonization time, the carbonization depth of concrete increases by $41.7 \% \sim 62.3 \%$.

(3) When the fly ash content varies in the range of $10 \%$ $20 \%$, the carbonation resistance of hybrid fiber concrete changes most sensitively. When the content of fly ash is less than $10 \%$, the carbonation resistance of hybrid fiber fly ash concrete can be the same as that of reference concrete. When the content of fly ash is more than $20 \%$, the carbonation resistance of hybrid fiber fly ash concrete is much lower than that of reference concrete.

(4) Through fitting the experimental data, the fitting curve and calculation formula of carbonation depth 
are obtained. Through verifying the calculation formula of carbonation depth, it is proved that the carbonation depth and calculation formula have certain accuracy, which can provide certain theoretical basis for practical engineering application.

\section{Data Availability}

The dataset generated and analyzed in the current research can be obtained from the corresponding authors upon request.

\section{Conflicts of Interest}

The authors declare that they have no conflicts of interest.

\section{Acknowledgments}

This research was funded by Natural Science Research Project of Colleges and Universities in Anhui Province (no. KJ2015A135). The authors are sincerely grateful to the Engineering Research Center of Underground Mine Construction, Ministry of Education, and the Anhui University of Science and Technology for providing the experiment conditions.

\section{References}

[1] A. Dindi, D. V. Quang, L. F. Vega, E. Nashef, and M. R. M. Abu-Zahra, "Applications of fly ash for $\mathrm{CO}_{2}$ capture, utilization, and storage," Journal of $\mathrm{CO}_{2}$ Utilization, vol. 29, pp. 82-102, 2019.

[2] Z. T. Yao, X. S. Ji, P. K. Sarker et al., "A comprehensive review on the applications of coal fly ash," Earth-Science Reviews, vol. 141, pp. 105-121, 2015.

[3] Y. He, Q. Luo, and H. Hu, "Situation analysis and countermeasures of China's fly ash pollution prevention and control," Procedia Environmental Sciences, vol. 16, pp. 690-696, 2012.

[4] S. K. Verma, K. Singh, A. K. Gupta et al., "Aromatic grasses for phytomanagement of coal fly ash hazards," Ecological Engineering, vol. 73, pp. 425-428, 2014.

[5] S. Abbas, M. A. Saleem, S. M. S. Kazmi, and M. J. Munir, "Production of sustainable clay bricks using waste fly ash: mechanical and durability properties," Journal of Building Engineering, vol. 14, pp. 7-14, 2017.

[6] C. Ferreira, A. Ribeiro, and L. Ottosen, "Possible applications for municipal solid waste fly ash," Journal of Hazardous Materials, vol. 96, no. 2-3, pp. 201-216, 2003.

[7] X. L. Duan and J. S. Zhang, "Mechanical properties, failure mode, and microstructure of soil-cement modified with fly ash and polypropylene fiber," Advances in Materials Science and Engineering, vol. 2019, Article ID 9561794, 13 pages, 2019.

[8] H. S. Shi and L. L. Kan, "Leaching behavior of heavy metals from municipal solid wastes incineration (MSWI) fly ash used in concrete," Journal of Hazardous Materials, vol. 164, no. 2-3, pp. 750-754, 2009.

[9] A. Zacco, A. Gianoncelli, R. Ardesi et al., "Use of colloidal silica to obtain a new inert from municipal solid waste incinerator (MSWI) fly ash: first results about reuse," Clean Technologies and Environmental Policy, vol. 14, no. 2, pp. 291-297, 2012.
[10] C. Collivignarelli and S. Sorlini, "Reuse of municipal solid wastes incineration fly ashes in concrete mixtures," Waste Management, vol. 22, no. 8, pp. 909-912, 2002.

[11] L. Bertolini, M. Carsana, D. Cassago, A. Quadrio Curzio, and M. Collepardi, "MSWI ashes as mineral additions in concrete," Cement and Concrete Research, vol. 34, no. 10, pp. 1899-1906, 2004.

[12] C.-G. Chen, C.-J. Sun, S.-H. Gau, C.-W. Wu, and Y.-L. Chen, "The effects of the mechanical-chemical stabilization process for municipal solid waste incinerator fly ash on the chemical reactions in cement paste," Waste Management, vol. 33, no. 4, pp. 858-865, 2013.

[13] M. Basu, M. Pande, P. B. S. Bhadoria, and S. C. Mahapatra, "Potential fly-ash utilization in agriculture: a global review," Progress in Natural Science, vol. 19, no. 10, pp. 1173-1186, 2009.

[14] N. L. Ukwattage, P. G. Ranjith, and M. Bouazza, "The use of coal combustion fly ash as a soil amendment in agricultural lands (with comments on its potential to improve food security and sequester carbon)," Fuel, vol. 109, pp. 400-408, 2013.

[15] J. S. Singh and V. C. Pandey, "Fly ash application in nutrient poor agriculture soils: impact on methanotrophs population dynamics and paddy yields," Ecotoxicology and Environmental Safety, vol. 89, pp. 43-51, 2013.

[16] V. C. Pandey, P. C. Abhilash, R. N. Upadhyay, and D. D. Tewari, "Application of fly ash on the growth performance and translocation of toxic heavy metals within Cajanus cajan L.: implication for safe utilization of fly ash for agricultural production," Journal of Hazardous Materials, vol. 166, no. 1, pp. 255-259, 2009.

[17] S. Wang and X. Fan, "Experimental study on indoor air pollution with activated fly ash treatment," Journal of North China Electric Power University, vol. 6, 2005.

[18] P. Davini, "Investigation of the $\mathrm{SO}_{2}$ adsorption properties of $\mathrm{Ca}(\mathrm{OH})_{2}$-fly ash systems," Fuel, vol. 75 , no. 6, pp. 713-716, 1996.

[19] M. T. Izquierdo and B. Rubio, "Carbon-enriched coal fly ash as a precursor of activated carbons for $\mathrm{SO}_{2}$ removal," Journal of Hazardous Materials, vol. 155, no. 1-2, pp. 199-205, 2008.

[20] G. Q. Lu and D. D. Do, "Adsorption properties of fly ash particles for NOx removal from flue gases," Fuel Processing Technology, vol. 27, no. 1, pp. 95-107, 1991.

[21] F. Mushtaq, M. Zahid, I. A. Bhatti, S. Nasir, and T. Hussain, "Possible applications of coal fly ash in wastewater treatment," Journal of Environmental Management, vol. 240, pp. 27-46, 2019.

[22] X. Chen, C. Si, and P. Fatehi, "Enhancement in biological treatment of pulping wastewater by fly ash," Chemosphere, vol. 210, pp. 1-9, 2018.

[23] M. Visa, L. Isac, and A. Duta, "Fly ash adsorbents for multication wastewater treatment," Applied Surface Science, vol. 258, no. 17, pp. 6345-6352, 2012.

[24] M. Namburath, G. Joshi, M. Cholemari, C. Shet, T. R. Sreekrishnan, and S. Veeravalli, "Feasibility study of indigenously developed fly ash membrane in municipal wastewater treatment," Aquatic Procedia, vol. 4, pp. 14921499, 2015.

[25] M. Visa, L. Andronic, and A. Duta, "Fly ash-TiO 2 nanocomposite material for multi-pollutants wastewater treatment," Journal of Environmental Management, vol. 150, pp. 336-343, 2015.

[26] D. Niu, Durability and Life Prediction of Concrete structures, Beijing Science Press, Beijing, China, 2003. 
[27] Y. Zhang, D. T. Niu, and S. B. Li, "Experimental study on fly ash concrete carbonation," Science Technology and Engineering, vol. 17, no. 27, pp. 275-278, 2017.

[28] Y. H. Cheng, H. W. Wang, and Y. Wang, "Preliminary research on carbonation resistance of fiber reinforced concrete," Journal of Building Materials, vol. 13, no. 6, pp. 792-795, 2010.

[29] M. C. Cheng, "Experimental research on carbonization of steel-poiypropylene fiber reinforced reactive powder concrete," Sichuan Building Science, vol. 44, no. 3, pp. 99-101, 2018.

[30] X. Zhang, R. Zhao, and S. Zhang, "Study on carbonation of steel-polypropylene hybrid fiber reinforced concrete," Sichuan Building Science, vol. 42, no. 6, pp. 120-123, 2016.

[31] B. Kim, A. J. Boyd, H.-S. Kim, and S.-H. Lee, "Steel and synthetic types of fibre reinforced concrete exposed to chemical erosion," Construction and Building Materials, vol. 93, pp. 720-728, 2015.

[32] W. Zhang, C. Yin, F. Ma, and Z. Huang, "Mechanical properties and carbonation durability of engineered cementitious composites reinforced by polypropylene and hydrophilic polyvinyl alcohol fibers," Materials, vol. 11, no. 7, p. 1147, 2018.

[33] C. F. Yuan, D. Y. Gao, and Y. Zhao, "Carbonation resistance of polypropylene fiber concrete exposed to high temperature," Bulletin of the Chinese Ceramic Society, vol. 32, no. 12, pp. 2405-2409, 2013.

[34] Q. W. Bi and P. F. Zhao, "Experimental study of the mechanical properties and performance of carbonation resistance of hybrid fiber reinforced light-weight aggregate concrete," Jurnal of Dalian Jiaotong University, vol. 29, no. 6, pp. 30-33, 2008.

[35] Y. F. Zhu and P. M. Wang, "Research on carbonation resistance of concrete containing large amount of fly ash," Journal of Building Materials, vol. 4, no. 12, pp. 319-323, 1999.

[36] H. L. Qiu and Q. Ye, "Effect of standard curing time during early stage on anti-carbonization capability of normal concrete," Journal of Zhejiang University of Technology, vol. 36, no. 4, pp. 436-440, 2008.

[37] B.-H. Jeon, H.-S. Kim, and S.-H. Lee, “A study on the evaluation of the carbonation resistance and properties ternary blended concrete according to replacement ratio of blast furnace slag and fly ash," Journal of the Korea Concrete Institute, vol. 30, no. 1, pp. 23-30, 2018.

[38] R. Kurda, J. de Brito, and J. D. Silvestre, "Carbonation of concrete made with high amount of fly ash and recycled concrete aggregates for utilization of $\mathrm{CO}_{2}$," Journal of $\mathrm{CO}_{2}$ Utilization, vol. 29, pp. 12-19, 2019.

[39] T. He, R. Xu, C. Chen, L. Yang, R. Yang, and Y. Da, "Carbonation modeling analysis on carbonation behavior of sand autoclaved aerated concrete," Construction and Building Materials, vol. 189, pp. 102-108, 2018.

[40] W. L. Tian, X. Y. Chang, H. Y. Wang et al., "Calculation model of carbonation depth in concrete cracks," Journal of Civil, Architectural and Environmental Engineering, vol. 39, no. 5, pp. 71-78, 2017.

[41] B. Q. Sun, G. Z. Liu, and Y. L. Liu, "Research on grey forecasting model for concrete carbonation," Journal of Bullding Materials, vol. 15, no. 1, pp. 42-48, 2012.

[42] J. L. Liu and Z. Fang, "Carbonation depth prediction of concrete structures based on inspection data," Journal of Civil, Architectural and Environmental Engineering, vol. 35, no. 3, pp. 70-74, 2013.

[43] GB/T50082-2009, Standard for Test Methods of Long-Term Performance and Durability of Ordinary Concrete (GB/
T50082-2009), China Architecture and Building Press, Beijing, China, 2009.

[44] F. P. Jia and B. B. Li, "Study on the effect of high temperature on the carbonization resistance property of fly ash concrete," Concrete, vol. 11, pp. 80-82, 2011.

[45] Z. H Shui, L. Q. Tu, W. B. Xu, and J. T. Ma, "Carbonation of fly ash concrete with expansive admixtures," Concrete, vol. 2, no. 52, pp. 55-59, 2011.

[46] J. Ran, J. X. Zhang, M. J. Yang, and J. g. Wang, "Compressive strength of concrete exposed to alternate carbonation and freezing-thawing cycles," Journal of Building Materials, vol. 20, no. 4, pp. 517-521, 2017.

[47] W. G. Xiao, Z. G. Guo, Z. P. Wu, X. Y. Tu, and Y. Peng, "Experimental research and theoretical analysis on carbonation resistance behavior of recycled aggregate concrete," Journal of Civil and Environmental Engineering, vol. 37, no. 6, pp. 47-53, 2015.

[48] X. Wang, Y.B. Wang, L.S. Yang, and X.F Zhu, "High-performance high-volume fly ash concrete," Bulletin of the Chinese Ceramic Society, vol. 32, no. 3, pp. 523-527, 2013.

[49] J. P. Chen, "Research on carbonation resistance of highperformance concrete containing large amount of fly ash," Construction Technology, vol. 39, no. 4, pp. 87-89, 2010. 